\title{
A Detailed Comparison of the Outer-loop Control Performance at the Receiving End Station of VSC Based HVDC Transmission System
}

\author{
Aleisawee M. Alsseid", Abdulrahman A.A. Emhemed, Mosa A. Abdesalam \\ College of Electronic Technology-Bani Walid, 38645 Bani Walid, Libya
}

Copyright $\mathrm{O} 2017$ by authors, all rights reserved. Authors agree that this article remains permanently open access under the terms of the Creative Commons Attribution License 4.0 International License

\begin{abstract}
The application of high voltage (HVDC) transmission for integrating large scale and/or off-shore wind generation systems with the electric grid is attractive in comparison to extra high voltage $\mathrm{AC}$ transmission systems due to a variety of reasons. A suitable control system is required for a VSC-HVDC system that provides good performance across a range of operating conditions. Two strategies are studied for their potential to enhance system robustness. The d-axis current control and DC power control are implemented in the outer-loop control at the receiving end of VSC-HVDC system. Small-signal analytical model is used to perform eigenvalues analysis and to design controllers. Both control techniques are investigated and the results are compared. An additional DC voltage droop control is added for both schemes. Its advantages were investigated. The droop gain and the cut off frequency of the DC voltage feedback filter are selected by analyzing the root locus of the analytical model to select the optimum values. It is established that d-axis current control with DC voltage droop control shows better performance practically for very weak AC system at both ends as well as with very long DC cable. The simulation results performed on PSCAD/EMTDC verify the feasibility of the control strategies effectively under different scenarios in order to confirm the obtained conclusions from analytical investigations.
\end{abstract}

Keywords DC Voltage Droop Control, High Voltage Direct Current (HVDC), Modeling Multi Terminal VSC HVDC

\section{Introduction}

Voltage Source Converter (VSC) based HVDC transmission system (VSC-HVDC), newly developed technology on power transmission [1], [2]. VSC-HVDC system offers a number of significant advantages over conventional line-commutated converters HVDC transmission system [3],[4]. Currently several installations of VSC-HVDC systems have been utilized in some application such as linking two asynchronous electrical power systems, power supply to off-shore drilling platform, empowering urban centers, improving power quality connecting distributed generation sources [5]. To fully exploit the capabilities of VSC-HVDC, a detailed analytical model and proper control design are required. Many research works on the operation and control of VSC-HVDC system have been carried on [6-9]. The VSC-HVDC with a suitable control scheme can offer an alternative means to enhance transient stability, to improve power oscillations damping, and to provide voltage support [10]. Small-signal analysis using linear techniques provides valuable information about the inherent dynamic characteristics of the power system and assists its design. The design of the control system is based on the detailed accurate analytical model [11]. The structures of the individual controllers have been presented in previous report [11]. The VSC-HVDC control system is split into the receiving (Terminal 1) and sending (Terminal 2) end station controllers which are performing on their connected converters. Developing this simulation platform provides the possibility of enhancing and analyzing the performance of the modeled system under different operating conditions. The complete detailed small signal model for the VSC-HVDC and design of its controllers has been discussed in [11]. The validation of the developed system has been provided in [12]. According to the related research and operation results of VSC-HVDC system, the following control modes are used for the converter of the VSC-HVDC system: DC voltage control mode, AC voltage control mode, DC current control mode, and DC power control mode. In Back-to-Back configuration of VSC-HVDC one converter is assigned to regulate the DC voltage, while the other converter can be chosen to control the DC current/ power. In the previous study, the DC voltage control mode was adapted to control the DC 
voltage at the sending end whereas the DC current model is implemented in outer-loop of the receiving station. Simulation results indicated that the employed control scheme did not provide a high performance control solution to VSC-HVDC systems, practically at very weak AC system strength at both ends as well as at very long DC cable. The main objective of this study is to present a detailed comparison of the outer-loop control performance at the receiving end station of VSC-HVDC system. Two different control methods d-axis current (Strategy 1) and DC power (Strategy 2) will be studied in the outer-loop control at the receiving end. In order to investigate and analyze the stability of the control system, the derived model will be used to obtain the root locus. The influence of the system parameters on the stability of the control system will be investigated using the root locus. A detailed comparison and investigation of the benefits of DC voltage droop control with both schemes will be carried out. Simulation study of detailed model of VSC-HVDC test system using PSCAD /EMTDC will be employed to verify the theoretical model and the selected control method.

\section{Analysis of Receiving End Control Modes}

A mathematical model of the control system is described for the VSC-HVDC [11]. A control system is developed combining inner current loop controller and outer controllers. In order to enhance system stability and the robustness of the developed model under different operation conditions such as: interconnected to very weak AC systems, AC system parameters changes, and very long DC cable two different control methods are employed in the outer control loop at the receiving end station. For further investigations the benefits of DC voltage droop technique with both schemes are carried out.

\subsection{Case Study-1}

The proposed control structure of strategy 1 is presented in Figure 1 while strategy 2 illustrates in Figure 2. Controls are implemented in a $d q$ reference frame that determines $d$ and $q$ axis components of the AC-side currents. In the inner control loop a Proportional-Integrator Differential (PID) controller is implemented, decoupled current compensation and voltage feed-forward compensation is adopted. The output of the control system (MT1d, MT1q), after transformation, into magnitude $(\mathrm{Mm})$ and phase shift $(M \varphi)$ represent the reference voltages for the pulse-width modulation (PWM). The phase looked loop is used to synchronized the converter firing angles with the $\mathrm{AC}$ system.

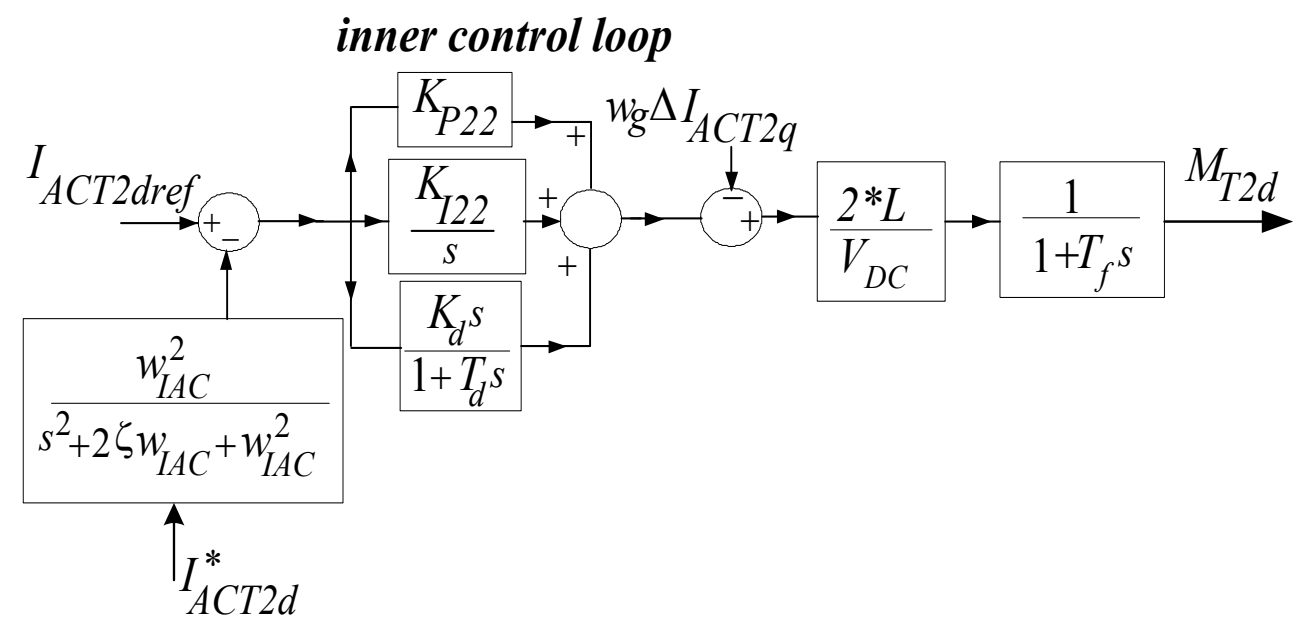

Figure 1. Diagram of d-axis current controller at inverter side 


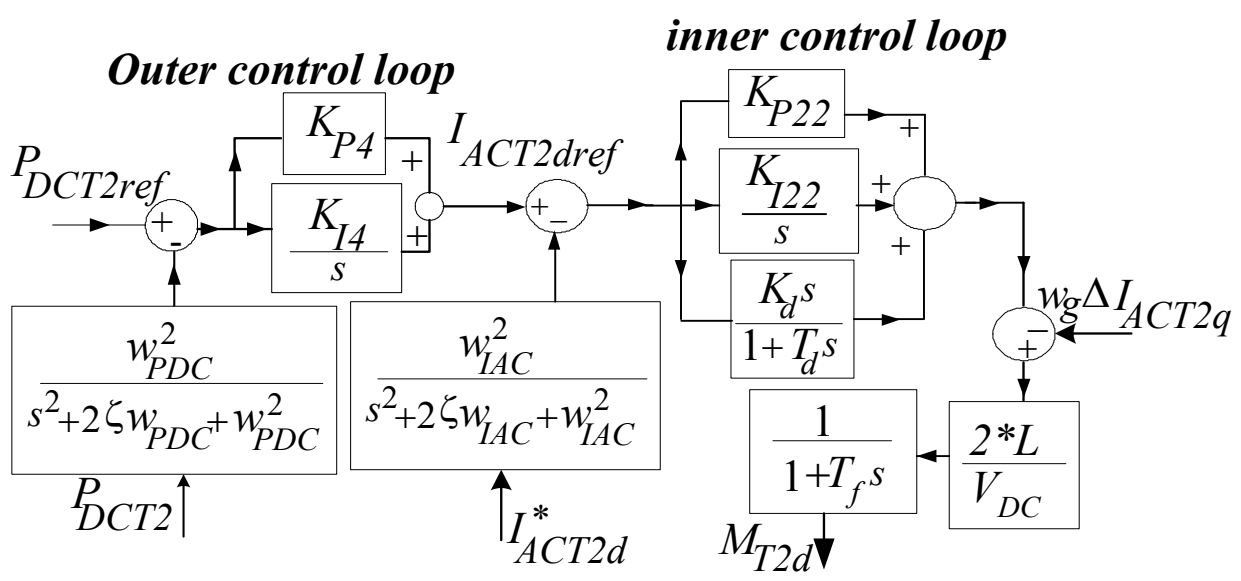

Figure 2. Diagram of DC power controller at inverter side

In strategy 1, under balanced steady-state condition the co-ordinates of voltage and current vectors in the synchronous reference frame are constant quantities where the $\mathrm{d}$ - axis is always coincident with the instantaneous voltage vector $\left(v_{d}=|v|, v_{q}=0\right)$. The d- axis current component contributes to the instantaneous active power whereas the q-axis current component is the instantaneous reactive current. The active power at the $\mathrm{AC}$ side of the converter is given by

$$
\begin{gathered}
P_{A C}=\frac{3}{2}\left(v_{d} i_{d}+v_{q} i_{q}\right) \\
P_{D C}=v_{D C} i_{D C}
\end{gathered}
$$

It is assumed that the converter $\mathrm{AC}$ power is equal to the DC power

$$
P_{A C}=P_{D C}
$$

Combing equations (1.0 and 1.1) yields

$$
v_{D C} i_{D C}=\frac{3}{2}\left(v_{d} i_{d}+v_{q} i_{q}\right)
$$

Since $v_{q}=0, \quad v_{D C} \cong v_{d}$ rearranging equation (1.3) yields

$$
v_{D C} i_{D C}=\frac{3}{2}\left(v_{d} i_{d}\right)
$$

From equation (1.4) can be deduced that

$$
i_{D C} \cong \frac{3}{2} i_{d}
$$

As illustrated in Figure 1 the d-axis current reference ( $\left.\mathrm{I}_{\mathrm{ACT} 2 \mathrm{dref}}\right)$ is supplied by the operator. As shown in the Figure 1 the measured $d$ component of AC system current $\left(\mathrm{I}^{*}{ }_{\mathrm{ACT2}} \mathrm{d}\right)$ is filtered and compared with the corresponding reference current that is specified by the user. The resultant error is feeding to the PID controller to generate the control signal. In strategy 2 , the active power measured from the system is filtered and compared to the reference value of active power and the error signal is input into PID controller to generate the control signal as demonstrated in Figure 2. In Figure 3, the locus of dominant eigenvalues (assuming controllers are tuned for $\mathrm{SCR}_{\mathrm{ACT} 1}=10$, $\mathrm{SCR}_{\mathrm{ACT} 2}=6.5$ with fixed $X / R=10$ ) is shown for $\mathrm{SCR}$ variation at terminal two $1 \leq \mathrm{SCR}_{\mathrm{ACT} 2} \leq 20$. The nominal $\mathrm{SCR}$ is marked by a circle (o), an asterisk (*) for $\mathrm{SCR}=1$, and $\mathrm{SCR}=20$ by a diamond $(\diamond)$. Key system parameters are detailed in Table-1 in the Appendix. The controller gains for both strategies without DC droop control are given in Table 2, and 3 in the Appendix. Figure 3a demonstrates the performance of Strategy 1 whereas Strategy 2 is presented in Figure $3 b$. It can be seen that the closest real eigenvalues are located on the left side of the s-plane. Therefore, the investigated system is always stable even at very low SCR at receiving end. It can be seen that branch "a" in Figure $3 \mathrm{a}$ is located further to left, compared with branch " $\mathrm{x}$ " in Figure $3 \mathrm{~b}$. Therefore, the stability margin is wider and the damping ratio of selected eigenvalues is improved as presented in Table- 4 by employing the $d$-axis current control scheme.

Table 1. Two Terminals Test System Parameters

\begin{tabular}{|c|c|c|}
\hline VSCT1 \& VSCT2 Rated Power & $P_{\text {VSCT1 rated }} / P_{\text {VSCT1 rated }}$ & $300 \mathrm{MW} / 300 \mathrm{MW}$ \\
\hline $\mathrm{V}_{\mathrm{ACT1}} \& \mathrm{~V}_{\mathrm{ACT} 2}$ Rated Voltage & $V_{A C T 1 \text { rated }} / V_{A C T 2 \text { rated }}$ & $220 \mathrm{KV} / 110 \mathrm{KV}$ \\
\hline DC Cable Parameters, 200Km length & $C_{D C} / L_{D C} / R_{D C}$ & $52 \mu \mathrm{F} / 0.1 \mathrm{H} / 3.0 \Omega$ \\
\hline AC Sy. Para, $\mathrm{V}_{\mathrm{ACT} 1}(\mathrm{SCR}=1, \mathrm{X} / \mathrm{R}=10)$ & $L_{A C T 1} / R_{A C T 1}$ & $0.51 \mathrm{H} / 1.605 \Omega$ \\
\hline AC sy. Para, $\mathrm{V}_{\mathrm{ACT2}}(\mathrm{SCR}=1, \mathrm{X} / \mathrm{R}=6.5)$ & $L_{A C T 2} / R_{A C T 2}$ & $0.127 \mathrm{H} / 5.7 \Omega$ \\
\hline Transformer Parameters-T1 & $S_{T 1 \text { rated }} / L_{A C T 1}$ & $300 \mathrm{MVa} / 0.12 \mathrm{p} . u$. \\
\hline Transformer Parameters-T2 & $S_{T 2 \text { rated }} / L_{A C T 2}$ & $300 \mathrm{MVa} / 0.12 \mathrm{p} . \mathrm{u}$. \\
\hline DC capacitance & $C_{D C T 1} / C_{D C T 1}$ & $40 \mathrm{uF} / 40 \mathrm{uF}$ \\
\hline
\end{tabular}


Table 2. Controller Parameters, Strategy 1 without DC Voltage Droop

\begin{tabular}{|c|c|c|c|}
\hline \multicolumn{2}{|c|}{ T1-CO. PARM. } & \multicolumn{2}{c|}{ T2-CO. PARM. } \\
\hline$K_{P 1}$ & 0.00932 & $K_{P 3}$ & 0.0095 \\
\hline$K_{I 1}$ & 2.5 & $K_{I 3}$ & 2.7 \\
\hline$K_{P 2}$ & -0.0035 & $K_{d T 2}$ & 1 \\
\hline$K_{I 2}$ & -0.1 & $K_{I 22 T 1}$ & 750 \\
\hline$K_{d T 1}$ & 1 & $T_{d T 2}$ & 0.01 \\
\hline$K_{P 22 T 1}$ & 200 & $K_{P 22 T 2}$ & 350 \\
\hline$K_{I 22 T 1}$ & 7500 & $K_{d c \_d r o o p T 2}$ & -0.025 \\
\hline$T_{d T 1}$ & 0.01 & $f_{-d c \_d r o o p T 2}$ & 120 \\
\hline
\end{tabular}

Table 3. Controller Parameters, Strategy 2 without DC Voltage Droop

\begin{tabular}{|c|c|c|c|}
\hline \multicolumn{2}{|c|}{ T1-CO. PARM. } & \multicolumn{2}{c|}{ T2-CO. PARM. } \\
\hline$K_{P 1}$ & 0.00932 & $K_{P 3}$ & 0.0095 \\
\hline$K_{I 1}$ & 2.5 & $K_{I 3}$ & 2.7 \\
\hline$K_{P 2}$ & -0.0035 & $K_{P 4}$ & 0.0025 \\
\hline$K_{I 2}$ & -0.1 & $K_{I 4}$ & 0.25 \\
\hline$K_{d T 1}$ & 1 & $K_{d T 2}$ & 1 \\
\hline$K_{P 22 T 1}$ & 200 & $K_{P 22 T 2}$ & 350 \\
\hline$K_{I 22 T 1}$ & 7500 & $K_{I 22 T 1}$ & 750 \\
\hline$T_{d T 1}$ & 0.01 & $T_{d T 2}$ & 0.01 \\
\hline
\end{tabular}

Table 4. Dominant System modes, $\mathrm{SCRT} 2=1, \mathrm{SCRT} 1=10$, without DC voltage droop dc-axis current control

\begin{tabular}{|c|c|c|c|}
\hline Mode & eigenvalue & Nat. Freq. $[\mathrm{Hz}]$ & Damp. Ratio \\
\hline 1 & $-26.07 \pm \mathrm{j} 63.92$ & 10.99 & 37.8 \\
\hline 2 & $-72.23 \pm \mathrm{j} 44.91$ & 13.54 & \\
\hline 3 & $-35.54 \pm \mathrm{j} 34.45$ & 7.88 & 46.3 \\
\hline \multicolumn{3}{|c|}{ DC power control } \\
\hline 1 & $-11.23 \pm \mathrm{j} 21.53$ & 3.87 & 83.8 \\
\hline 2 & $--72.16 \pm \mathrm{j} 47.0$ & 13.71 & 64.0 \\
\hline 3 & $-58.09 \pm \mathrm{j} 69.72$ & 14.45 & \\
\hline
\end{tabular}

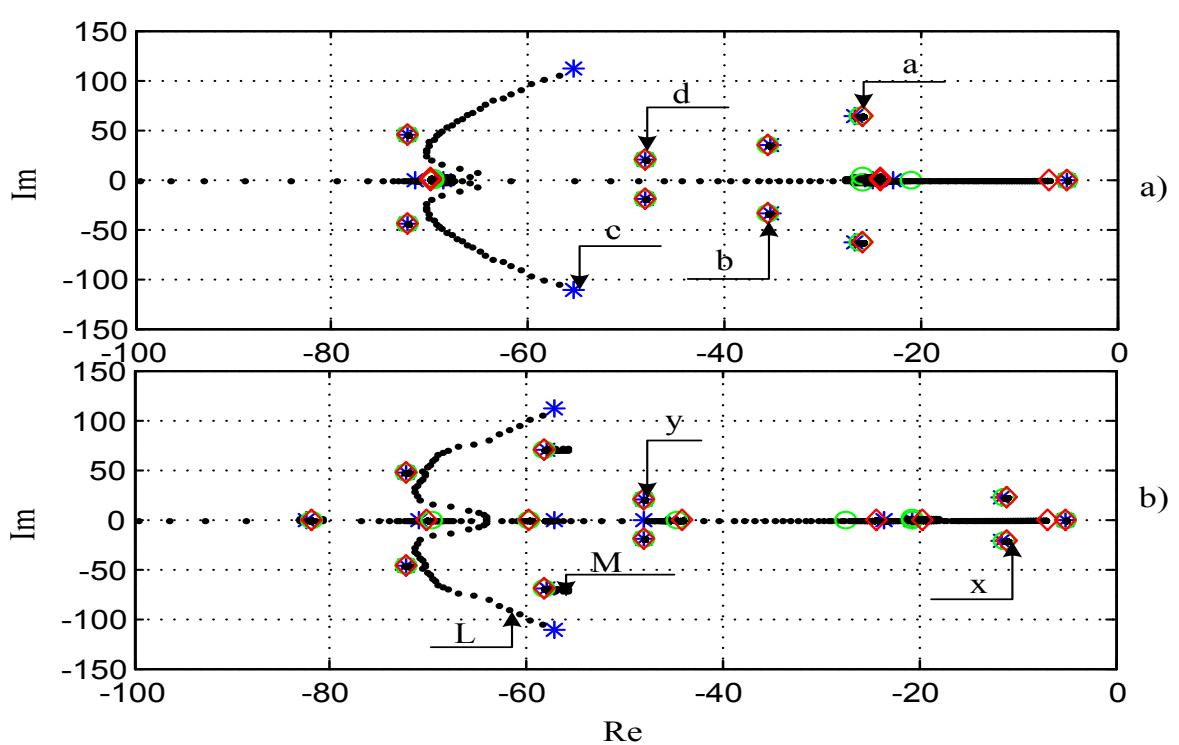

Figure 3. Root locus of the original test system with reduction of $(\mathrm{SCRT} 2=20 \rightarrow 1$ ), without DC voltage droop, a) d-axis current control, b) DC power. 


\section{DC Voltage Droop Control}

The objective of this section is to investigate the stability of the system for the chosen values of droop gain and the influence of the cutoff frequency of DC voltage filter. The droop control strategy was proposed for regulating CSC-MTDC networks [13]. This method can also be applied for VSC-MTDC networks [14]. A droop DC voltage feedback is implemented in DC transmission networks to improve DC grid stability [15]. In this study, a DC voltage droop control is added in the outer control at terminal two, as shown in Figure 4 and Figure 5. A detailed small-signal state space model of VSC-HVDC system including DC voltage droop scheme at the inverter side is developed. The droop stability analysis will be carried out by employing the derived model to obtain the root locus. The influence of the DC voltage droop control parameters on the system stability will be investigated. With reference to the Figure 4 the bandwidth of DC voltage droop control $\left(\omega_{D C}\right.$ droop $)$ is determined. It is calculated with $\omega_{D C_{\text {_droop }}}=2 * \pi * f_{D C_{\text {_droop }} \text {, where }} f_{D C_{\text {_droop }}}$ is the cutoff frequency and $\xi_{D C \_ \text {droop }}$ stands for the damping factor of the filter. Initially, these value are assumed as follows $f_{D C \_ \text {droop }}=30 \mathrm{~Hz}$, and $\xi_{D C \_ \text {droop }}=1$ in order to select the proper value of the $\mathrm{DC}$ voltage droop gain. By determining the $\omega_{D C \text { droop }}$ the root locus method is used to select the optimum DC voltage droop gain. The controller gains for both strategies with DC droop control are given in Table 5, and 6 in the Appendix. It is observed that as the DC voltage droop gain is increased the system stability is improved and then for very high gain the eigenvalues moved towards unstable region making the system more oscillatory and ultimately the stability is deteriorated as depicts in Figure 6. Therefore, the optimum values of the DC voltage droop gain is chosen based on the locations of eigenvalues as presented in Figure 6 marked by a circle (o) which has a value of -0.025 . The root loci for cut-off frequency changing from $0 \mathrm{~Hz}$ to $1 \mathrm{kHz}$ are shown in Fig. 7. It can be seen that a satisfactory regulation performance is observed at the varied frequency ranges. A zoomed view at lower frequency shows that as the $f_{D C}$ droop is increased the system stability margin is improved and then for higher value it is reduced. Thus, the optimum value is chosen based on the locations of eigenvalues as presented in Figure 7 marked by a square ( $\square$ ) which is correspondent to $120 \mathrm{~Hz}$.

Table 5. Controller Parameters, Strategy 1 with DC voltage droop

\begin{tabular}{|c|c|c|c|}
\hline \multicolumn{2}{|c|}{ T1-CO. PARM. } & \multicolumn{2}{c|}{ T2-CO. PARM. } \\
\hline$K_{P 1}$ & 0.00932 & $K_{P 3}$ & 0.0095 \\
\hline$K_{I I}$ & 2.5 & $K_{I 3}$ & 2.7 \\
\hline$K_{P 2}$ & -0.0035 & $K_{P 4}$ & 0.0025 \\
\hline$K_{I 2}$ & -0.1 & $K_{I 4}$ & 0.25 \\
\hline$K_{d T 1}$ & 1 & $K_{d T 2}$ & 1 \\
\hline$K_{P 22 T 1}$ & 200 & $K_{P 22 T 2}$ & 350 \\
\hline$K_{I 22 T 1}$ & 7500 & $K_{I 22 T 1}$ & 750 \\
\hline$T_{d T 1}$ & 0.01 & $T_{d T 2}$ & 0.01 \\
\hline
\end{tabular}

Table 6. Controller Parameters, Strategy 2 with DC voltage droop

\begin{tabular}{|c|c|c|c|}
\hline \multicolumn{2}{|c|}{ T1-CO. PARM. } & \multicolumn{2}{c|}{ T2-CO. PARM. } \\
\hline$K_{P 1}$ & 0.00932 & $K_{P 3}$ & 0.0095 \\
\hline$K_{I 1}$ & 1.9 & $K_{I 3}$ & 2.7 \\
\hline$K_{P 2}$ & -0.0035 & $K_{p 4}$ & 0.0025 \\
\hline$K_{I 2}$ & -0.1 & $K_{I 4}$ & 0.25 \\
\hline$K_{d T 1}$ & 1 & $K_{d T 2}$ & 1 \\
\hline$K_{P 22 T 1}$ & 200 & $K_{P 22 T 1}$ & 350 \\
\hline$K_{I 22 T 1}$ & 7500 & $K_{I 22 T 2}$ & 7500 \\
\hline$T_{d T 1}$ & 0.01 & $T_{d T 2}$ & 0.01 \\
\hline & & $K_{d c \_d r o o p T 2}$ & -0.95 \\
\hline & & $f_{d c \_d r o o p T}$ & 120 \\
\hline
\end{tabular}

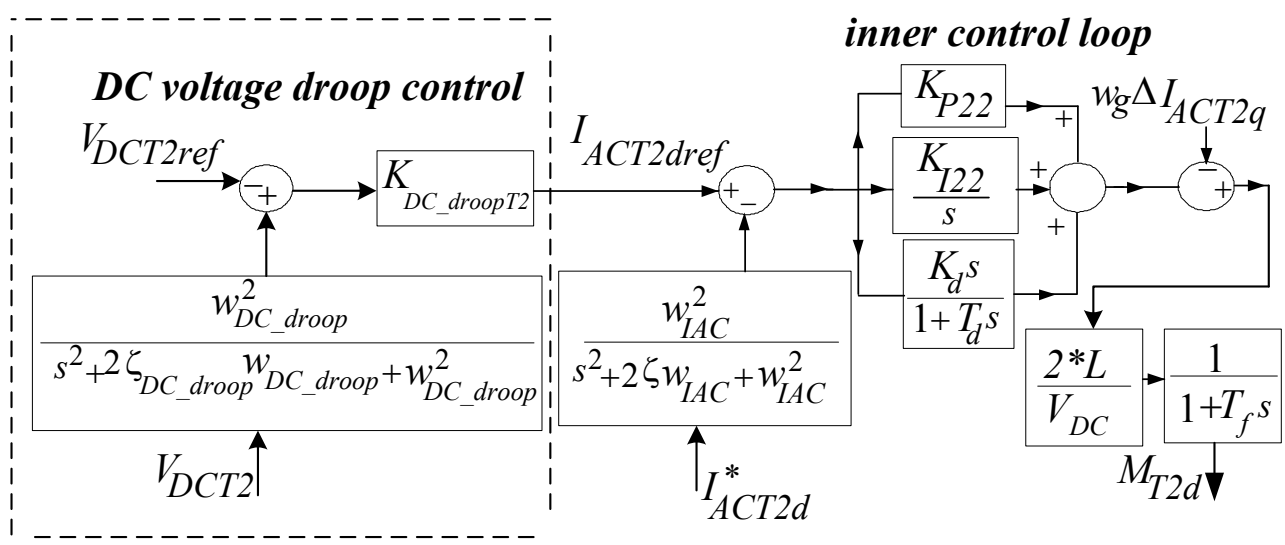

Figure 4. Diagram of d-axis current control with DC voltage droop control at inverter side 


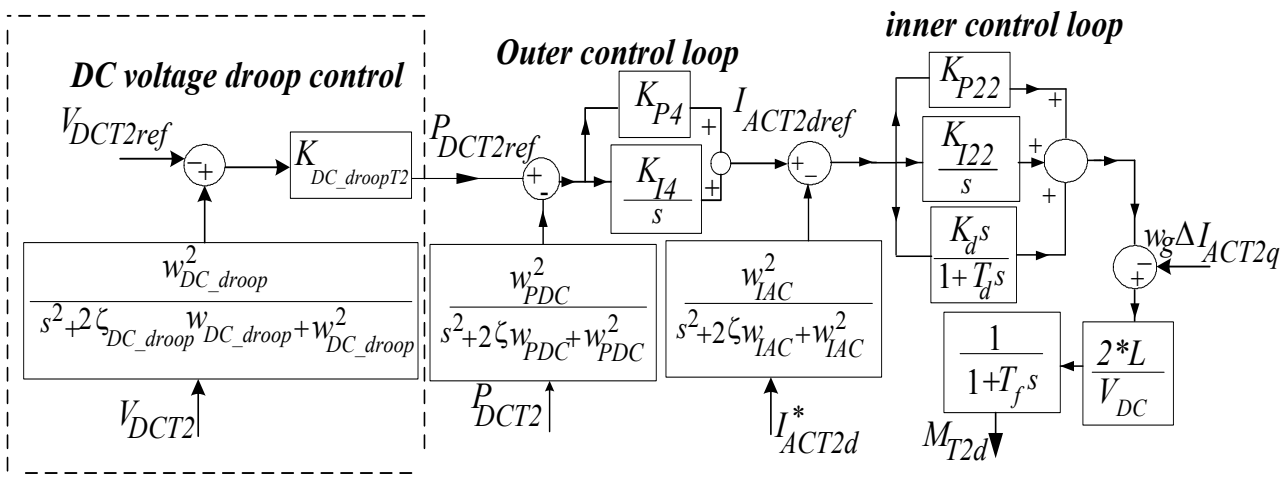

Figure 5. Diagram of DC power with DC voltage droop control at inverter side give values for controller gains.

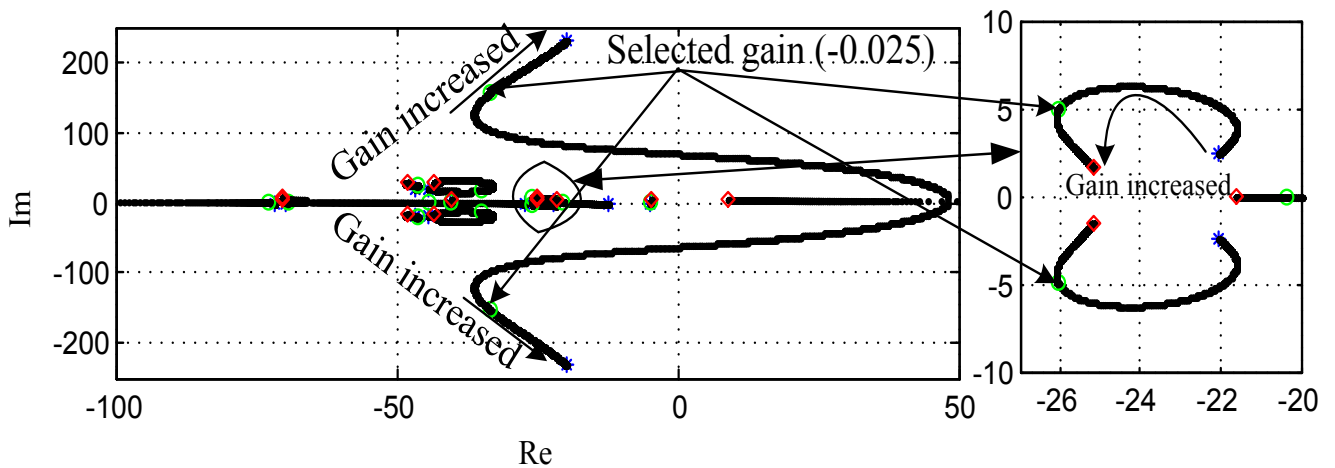

Figure 6. Root locus of modeled system as a function of DC voltage droop gain variation, employing d-axis current control with DC voltage droop control.

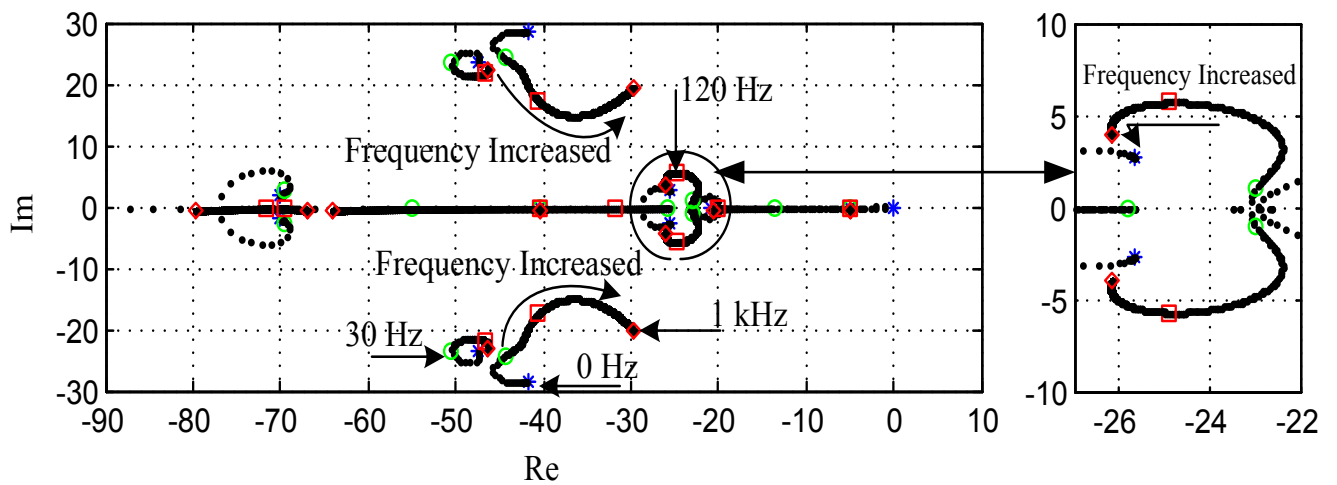

Figure 7. Root locus of the system with DC voltage droop control with variation of cut-off frequency, $\left(\mathrm{K}_{\mathrm{DC} \_ \text {droopT2 }}=-0.025\right),(* \rightarrow 1 \mathrm{~Hz}, \mathrm{O} \rightarrow 30 \mathrm{~Hz}$, $\square \rightarrow 120 \mathrm{~Hz}$, and $\diamond \rightarrow 1 \mathrm{kHz}$ ), employing d-axis current control with DC voltage droop control.

Figure 8a represents the performance of the d-axis current control with the DC voltage droop control. In comparison with the original system Figure $3 \mathrm{a}$, it is seen that DC voltage droop control can significantly improve the system stability where the nearest dominant system modes branch "a1" are shifted further to the left half-plane due to the advantages of the DC voltage droop control as depicts in Figure 8a. The eigenvalues associated with branch "b" in Figure 7a is moved further to the left compared with Figure 8a. It is observed that branch "c1" in Figure 8a becomes shorter than the branch "c" in Figure 7a. Similarly the same procedure is carried out in order to inspect the benefits of the DC voltage droop with the DC power mode as illustrated in Figure 8b. It is observed that from Figure $8 \mathrm{~b}$ very little or no advantage is established with DC voltage droop control especially at very low frequency. The impact of DC voltage droop control on the specific modes can be studied in Table-7. From Table-7 it can be noticed that the damping ratio and the complex pole location are significantly improved compared with Table-4.

Table 7. Dominant System modes, SCRT2=1, SCRT1=10, with DC voltage droop

\begin{tabular}{|c|c|c|c|}
\hline \multicolumn{4}{|c|}{ d-axis current control } \\
\hline Mode & eigenvalue & Nat. Freq. [Hz] & Damp. Ratio \\
\hline 1 & $-30.3 \pm \mathrm{j} 19.2$ & 5.71 & 84.6 \\
\hline \multicolumn{4}{|c|}{ DC power control } \\
\hline Mode & eigenvalue & Nat. Freq. [Hz] & Damp. Ratio \\
\hline 1 & $-15.19 \pm \mathrm{j} 23.36$ & 4.44 & 54.5 \\
\hline
\end{tabular}




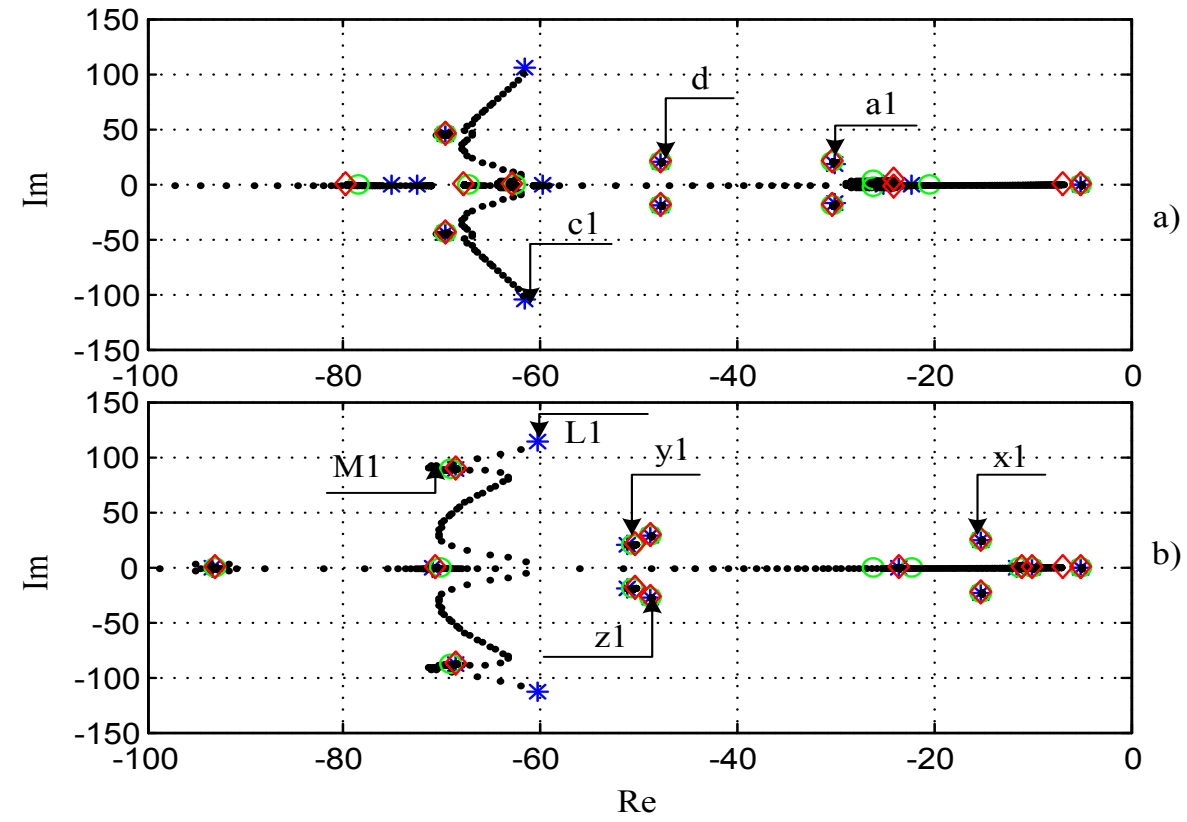

Figure 8. Root locus with DC voltage droop with reduction of $(\mathrm{SCRT} 2=20(\diamond) \rightarrow 1(*))$, with DC voltage droop a) d-axis current, b) DC power.

It is concluded that the $d$-axis AC current control with the DC voltage droop control results in moving the system poles further to the left of the S-plane as proven in Figure 8a. Thus, an extended stable operation of the control system can be achieved by employing the d-axis current control with DC voltage droop control

\section{Interconnection of Two Very Weak AC Systems}

In contrast to the conventional HVDC transmission system, the VSC-HVDC system has the potential to be connected to very weak AC systems. Moreover, it has the capability to generate or consume reactive power depending on the operating conditions. As proven in Section 4.0, the d-axis current control with the DC voltage droop shows better performance than the DC power mode. Therefore, the robustness of the selected control system (strategy 1 with DC voltage droop control) must be investigated to ensure that in all operation conditions the system capable to remains stable and still gives satisfactory results for a range of $\mathrm{AC}$ grid strengths. In this case a 300 MW VSC-HVDC link is considered to interconnect two very weak ac systems, where the AC system strength at both end terminals equal one $\left(\mathrm{SCR}_{\mathrm{T} 1}=\mathrm{SCR}_{\mathrm{T} 2}=1\right.$, $\mathrm{X} / \mathrm{RT} 2=6.5$ ). The detailed parameters of the test system stations are given in Table 3 and Table 4 in the Appendix. Figure 9 shows the eigenvalues movement following reduction in the AC grid strength. Figure 9a demonstrate the performance of the control system as the SCRT2 reduces $(20 \rightarrow 1)$ while the SCRT1=1. Figure $9 \mathrm{~b}$ presented the case when the SCRT2 $=1$ and SCR1 varied $(20 \rightarrow 1)$. It can be noticed that a satisfactory performance is achieved even if the system strength is very low at both terminals. The responses of the detailed PSCAD model and the linearized model are demonstrated in Figure 10. It can be noticed, good matching responses are confirmed with fast response and this gives confidence to the eigenvalue analysis given in Figure 8. It is confirmed that a satisfactory response is established even if the $\mathrm{AC}$ system strength at both terminals are very low. 


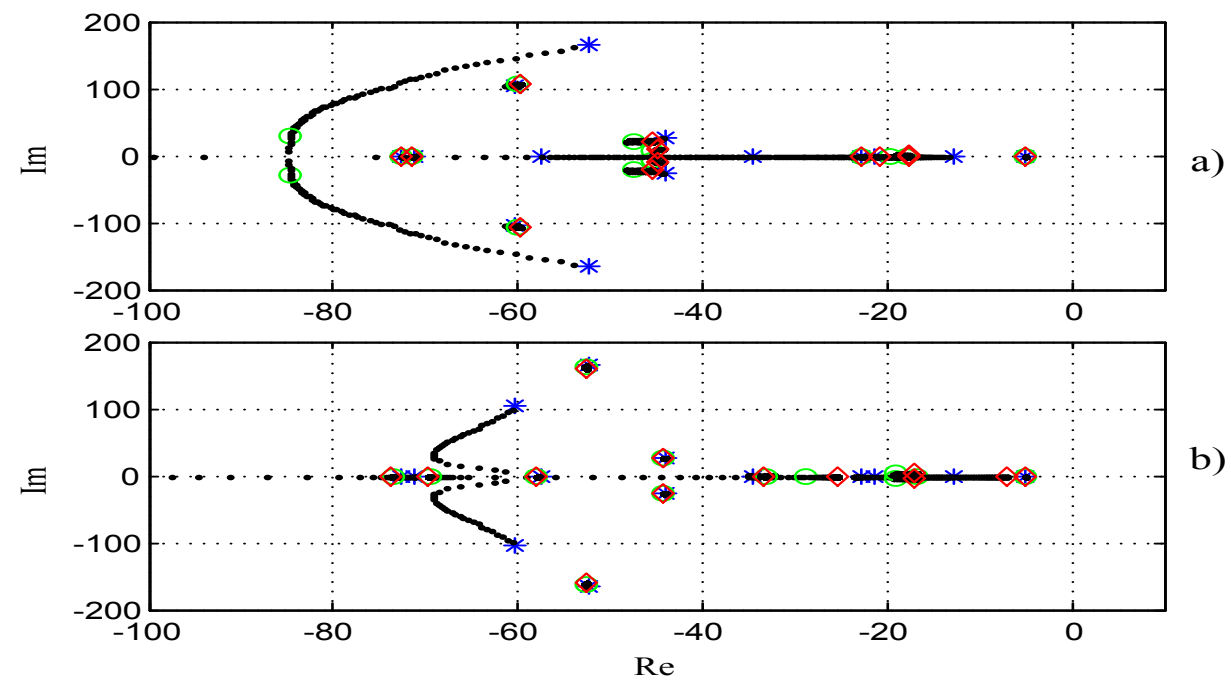

Figure 9. Root locus with changes in the AC system strength for interconnection of two very weak AC systems with d-axis current control and DC voltage droop control a) At sending end as $\operatorname{SCR}_{\mathrm{T} 2}(20 \rightarrow 1)$ and $\mathrm{SCR}_{\mathrm{T} 1}=1$, b) At receiving end as $\mathrm{SCR}_{\mathrm{T} 1}(20 \rightarrow 1)$ and $\mathrm{SCR}_{\mathrm{T} 2}=1$
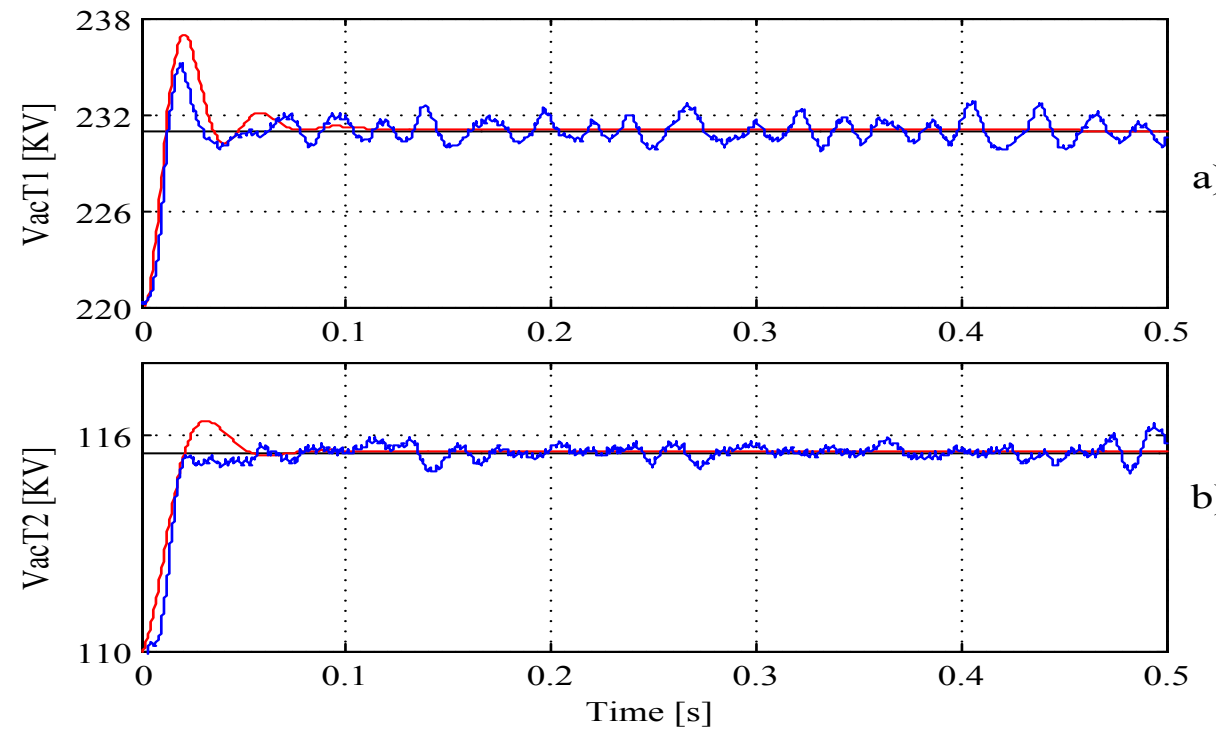

Figure 10. Verification of test system responses at $\mathrm{SCRT} 1=\mathrm{SCRT} 2=1$ (MATLAB Analytical model and Detailed PSCAD model) with d-axis current control and DC voltage droop following a $\%$ step change on AC voltage reference, a) $\mathrm{V}_{\mathrm{ACT} 1}$, b) $\mathrm{V}_{\mathrm{ACT} 2}$

\section{Robustness against DC Cable Parameter}

To investigate the robustness against the DC cable parameters, the following study is carried out. In this studied case the test system parameters and the control gain are the same as Figure 10 except the DC cable length is increased by ten times $\left(2000 \mathrm{~km}, R_{D C}=30 \Omega, L_{D C}=1 \mathrm{H}\right.$, and $\left.C_{D C}=520 \mathrm{uF}\right)$. In Figure 11 , the locus of dominant eigenvalues (assuming controllers are tuned for $\mathrm{SCR}_{\mathrm{ACT} 1}=10, \mathrm{SCR}_{\mathrm{ACT} 2}=6.5$ with fixed $X / R=10$ ) is shown for $\mathrm{SCR}$ variation at terminal two $1 \leq \mathrm{SCR}_{\mathrm{ACT} 2} \leq 20$. The nominal SCR is marked by a circle (o), an asterisk (*) for $\mathrm{SCR}=1$, and $\mathrm{SCR}=20$ by a diamond $(\diamond)$. Figure 11 a shows the resulting root locus for long DC cable without DC voltage droop control scheme. It is observed that from the root locus illustrated in Figure 11a that the system is always unstable because branch "G" always lies in the right half-plane Also branch "H" in Figure 11a is very close to the origin. Figure $11 \mathrm{~b}$ depicts the resulting root locus for long DC cable with DC voltage droop control scheme. As presented in Figure $11 \mathrm{~b}$ the system shows satisfactory performance at very long DC cable where all the eigenvalues are located in the stable region. It is clearly shown that branch " $G$ " is moved further to the left half-plane. As seen from Figure 11b, branch " $\mathrm{H} 1$ " is shifted towards the left half-plane. It is confirmed that from Figure $11 \mathrm{~b}$ the stability region becomes wider due to the advantages of DC voltage droop control. It can be observed that as the DC cable length increased by factor 10, the root locus branch "H1" becomes longer compared with Figure $8 \mathrm{a}$, branch "a1" (original test system). Since this branch "H1" is located far way from the imaginary axis and does not cause any stability problem. 


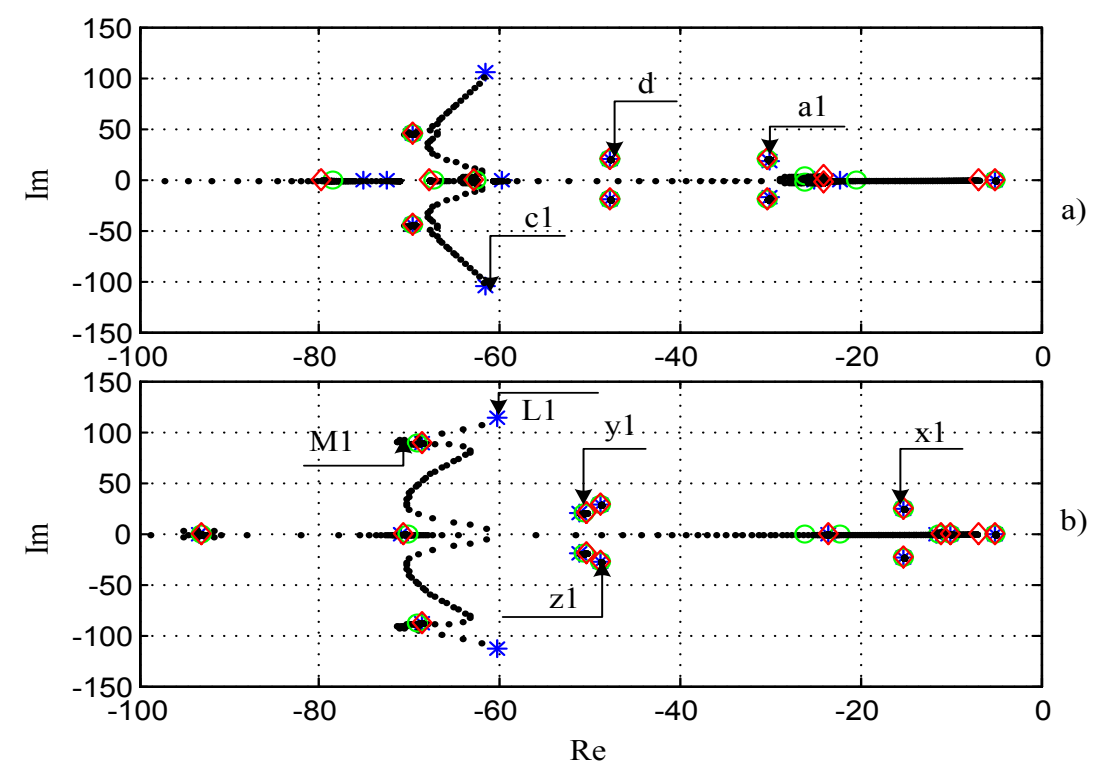

Figure 11. Root locus with changes in the system strength at receiving end, $\mathrm{SCR}_{\mathrm{T} 2}(20 \rightarrow 1), \mathrm{SCRT}=10$, with $\mathrm{DC}$ voltage droop control, DC cable $2000 \mathrm{~km}, 2 \mathrm{kA}$ a) without DC voltage droop control, b) with DC voltage droop control.
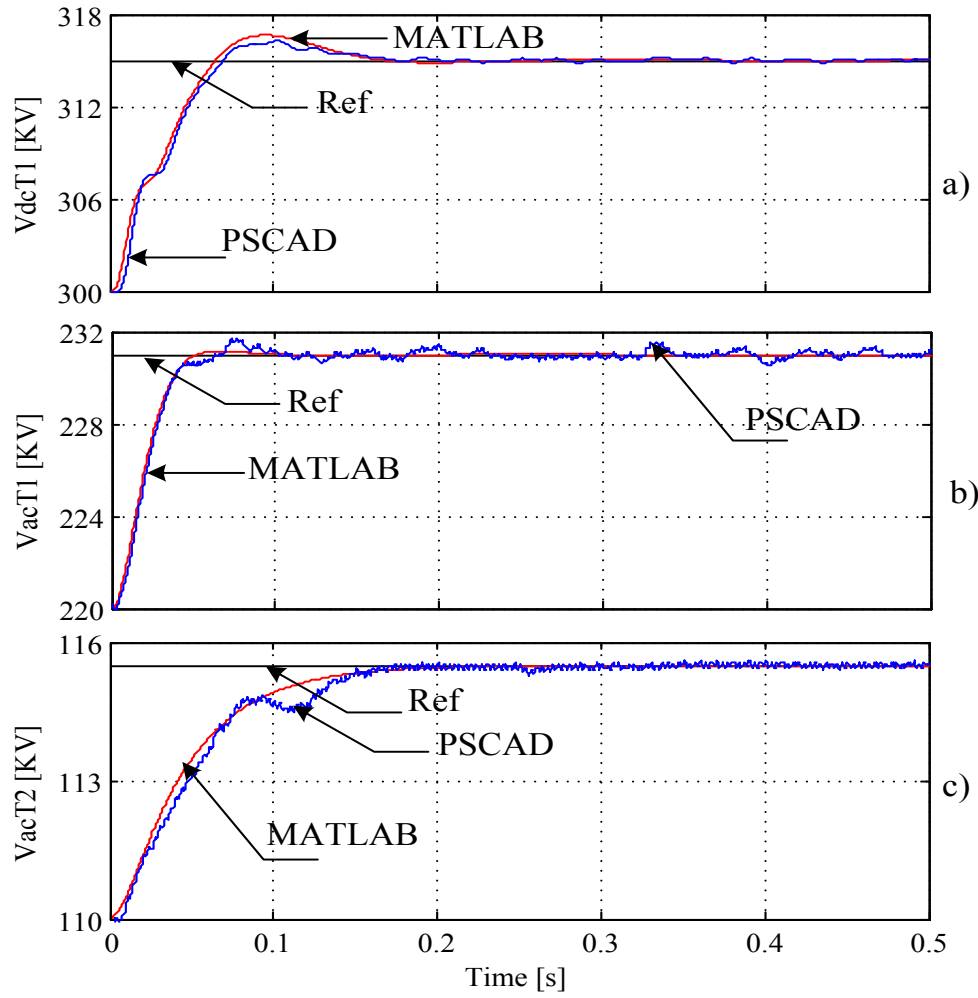

Figure 12. Analytical model verification following a 5\% step change, with d-axis current control and DC voltage droop control, DC cable length $2000 \mathrm{~km}, \mathrm{SCRT1}=10, \mathrm{SCRT} 2=6.5$ a) DC voltage $\mathrm{V}_{\text {dcT1 }}$, b) AC voltage $\mathrm{V}_{\text {acT1 }}$, c) AC voltage $\mathrm{V}_{\text {acT2 }}$

\subsection{Simulation with Detailed PSCAD Model}

In this section the performance of the modeled system (detailed analytical model) with the d-axis current control and DC voltage droop for very long DC cable are confirmed with the detailed PSCAD/EMTDC simulation. The controller gains used in PSCAD model are the same as presented in Table -3 and Table -4 in the Appendix. From
Figure 12, it can be observed the PSCAD responses are similar to responses of the detailed analytical model. Therefore it can be concluded that the PSCAD model confirms the accuracy of the analytical models. It is also observed the DC/AC voltages references are well controlled and a satisfactory response at long DC cable is confirmed. 


\section{Conclusions}

In this study, the robustness of two different controller designs is investigated, where the detailed linear analytical model of VSC-HVDC is employed. The AC system strength is varied to test controller robustness. It is presented that both d-axis current control and the DC power control schemes show satisfactory operation at very low SCR at the receiving end. In terms of comparison, the $d$-axis current control shows better performance than the DC power control mode. It is concluded that the stability margin and the damping ratio of dominant system modes are improved by employing the d-axis current control scheme. A DC voltage droop technique is proposed and implemented with both schemes. The system performance is investigated regarding their robustness at a very weak $\mathrm{AC}$ grid strength at both stations. It is proven that the $d$-axis AC current control with the DC voltage droop control results in moving the system poles further to the left of the S-plane. The damping ratios of dominant system modes are improved and the stability margin is wider. In contrast, it is observed that very little or no advantage is established from strategy 2 with DC voltage droop control. For best results, the performance of the selected control strategy (d-axis current control with DC voltage droop control) is considered regarding its robustness at a very weak $\mathrm{AC}$ grid strength at both stations as well as at very long DC cable. The stability analysis is shown that the DC voltage droop control system with the d-axis current control loop results in a better dynamics performance operation of the VSC-HVDC system. This control strategy offers many features such as insensitivity to parameter variations and significant robustness which are attractive for M-VSC-HVDC. The capability of the scheme is proven at very weak AC system strength at both stations and at very long DC cable and thus providing very fast dynamic response. To verify the results of the detailed small-signal linearised model of VSC-HVDC, a detailed PSCAD model using d-axis current control and DC voltage droop technique is developed in PSCAD/EMTDC. Good matching is observed between PSCAD model and analytical model responses with stable operation of the system indicates the efficacy of the proposed DC droop controller

\section{Acknowledgements}

The author gratefully acknowledges support from professor D. Jovcic, School of Engineering, University of Aberdeen, Aberdeen. UK.

\section{REFERENCES}

[1] Szuki Hirokazu and Aajima Tatsuhito, "Development and testing of prototype models for a high-performance $300 \mathrm{MW}$ self-commutated AC/DC converter," IEEE Trans. on Power Delivery, vol. 12, pp.1589-1597, Apr. 1997.

[2] Gengyin Li, Pengfei Lv, Guangkai Li, et al, "The new development and prospects for HVDC light," Automation of Electric Power System, vol. 27, no. 4, pp. 77-81, Feb. 2003.

[3] Ooi B T, Xiao Wang. "Boost type PWM HVDC transmission system" IEEE Transactions on Power Delivery, Vol.6, No.1, pp.1557-1563, 1991

[4] F. Schettler, H. Huang, and N. Christl, "HVDC transmission systems using voltage source converters-design and applications," IEEE Power Engineering Society Summer Meeting, No.2, pp.715-720, 2000

[5] Lars Weimers, "HVDC Light: a new technology for a better environment," IEEE Power Engineering Review, vol. 18, no. 8, pp.19-20, Aug. 1998

[6] Zheng Chao, Zhou Xiaoxin, "Small signal dynamic modeling and damping controller designing for VSC based HVDC" Proceedings of the CSEE, Vol.26, No.2, pp.7-12, 2006.

[7] Hairong Chen, Zheng Xu, Fan Zhang, "Nonlinear control for VSC based HVDC system," IEEE Power Engineering Society General Meeting, pp.1-5, 2006

[8] Yin Ming, Li Gengyin, Niu Tongyi, et al. "Continuous-time state-space model of VSC-HVDC and its control strategy" Proceedings of the CSEE, Vol.25, No.18, pp.34-39, 2005.

[9] A. Rahmati, A. Abrishamifar, E. Abiri, "Direct power control of an VHDC system based on VSCs" IEEE ICIT 2006, pp.2984-2989, 2006.

[10] H. F. Latorre, M. Ghandhari, and L. Söder, "Active and reactive power control of a VSC-HVDC," in Electric Power Systems Research, vol. 78, pp. 1756-1763, 2008.

[11] A.M. Alsseid, "Modelling and Control Design", internal report Aberdeen University, Oct. 2010

[12] A.M. Alsseid, "Modelling validation", internal report Aberdeen University, Oct. 2010

[13] B.K. Johnson, R.H. Lasseter, F.L. Alvarado and R. Adapa, "Expandable Multiterminal DC Systems Based on Voltage Droop", IEEE Trans. Power Delivery, vol. 8, no. 4, pp. 1926-1932, Oct. 1993.

[14] Hendriks R.L., van der Meer A.A., Kling W.L. "Impact on System Stability of Different Voltage Control Schemes of Wind Power Plants Connected Through AC and VSC-HVDC Transmission", Proc. of the Nordic Wind Power Conference, Bornholm, 2009

[15] D. Jovcic, and B.T.Ooi, "Developing DC Transmission Networks using DC Transformers," IEEE TRANSACTIONS ON POWER DELIVERY, VOL. 25, NO. 4, OCTOBER 2010, pp. 2535-2543. 